\title{
A Organização do Trabalho Pedagógico no Oeste do Pará: Discussões no Contexto Pandêmico
}

\author{
The Organization of Pedagogical Work in The West of Pará: \\ Discussions in the Pandemic Context
}

\section{La Organización del Trabajo Pedagógico en el Oeste de Pará: Discusiones en el Contexto Pandémico}

Lucas de Vasconcelos Soares ${ }^{1}$; Maria Lília Imbiriba Sousa Colares²; Anselmo Alencar Colares ${ }^{3}$

\section{RESUMO}

O estudo visa analisar a atuação de gestores educacionais frente à dinâmica de organização do trabalho pedagógico no curso de uma pandemia, revelando práticas, desafios e o lugar da formação nesse processo. Utiliza-se como lócus a região Oeste do Estado do Pará. As análises resultam de pesquisa empírica, contemplando a percepção de gestores educacionais por meio de formulário eletrônico. Os resultados obtidos revelam que optou-se pela continuidade das atividades, via ensino remoto, projetando nos gestores o desafio de organizar, junto à equipe pedagógica, a dinâmica do processo ensino-aprendizagem a partir do uso das ferramentas tecnológicas disponíveis, bem como na elaboração de apostilas com conteúdos dos livros didáticos; não houve formação específica para esse momento; e aumentou-se a demanda de trabalho, registrando reivindicações, por parte das famílias dos estudantes, quanto às metodologias utilizada pelas escolas. Somandose aos dilemas já existentes - minimização de recursos, ausência de participação e autonomia, etc. - o contexto pandêmico projetou nos gestores o desafio de se reinventar em sua atuação profissional.

Palavras-chave: Organização do Trabalho Pedagógico; Gestão Educacional; Formação; Pandemia.

\begin{abstract}
The study aims to analyze the performance of educational managers in the face of the dynamics of organizing pedagogical work in the course of a pandemic, revealing practices, challenges and the place of training in this process. The Western region of the State of Pará is used as locus. The analyzes result from empirical research, contemplating the perception of educational managers through an electronic form. The results obtained reveal that it was decided to continue the activities, via remote teaching, projecting on managers the challenge of organizing, together with the pedagogical team, the dynamics of the teaching-learning process from the use of available technological tools, as well as in the elaboration handouts with textbook content; there was no specific training for that moment; and the demand for work increased, registering demands by the students' families regarding the methodologies used by schools. Adding to the existing dilemmas - minimization of resources, lack
\end{abstract}

\footnotetext{
${ }^{1}$ Mestrando em Educação pelo Programa de Pós-graduação em Educação (PPGE) da Universidade Federal do Oeste do Pará, Santarém/PA - Brasil.

${ }^{2}$ Doutora em Educação e docente do curso de Pedagogia, do Programa de Pós-graduação em Educação e do Programa de Pós-graduação em Educação da Amazônia/PGEDA, polo Ufopa. Coordenadora Adjunta do PPGE/Ufopa e do Grupo de Estudos e Pesquisas "História, Sociedade e Educação no Brasil HISTEDBR/UFOPA". Vice-presidente da Região Norte da Sociedade Brasileira de Educação Comparada/SBEC (2020-2022). Bolsista do CNPq - Brasil (no do processo 304018/2018-0), Santarém/PA - Brasil.

3 Doutor em Educação. Professor Titular da Universidade Federal do Oeste do Pará. Docente do Programa de Pós-graduação em Educação PPGE/Ufopa e do Programa de Pós-graduação em Educação na Amazônia Doutorado Acadêmico (Associação em Rede - Polo Santarém/Ufopa). Líder do Grupo de Estudos e Pesquisas "História, Sociedade e Educação no Brasil - HISTEDBR/UFOPA", Santarém/PA - Brasil.
} 
of participation and autonomy, etc. - the pandemic context projected on managers the challenge of reinventing themselves in their professional performance.

Keywords: Organization of Pedagogical Work; Educational management; Formation; Pandemic.

\section{RESUMEN}

El estudio tiene como objetivo analizar el desempeño de los gestores educativos ante la dinámica de organización del trabajo pedagógico en el transcurso de una pandemia, revelando prácticas, desafíos y el lugar de la formación en este proceso. Se utiliza como locus la región occidental del estado de Pará Los análisis son el resultado de una investigación empírica, contemplando la percepción de los gestores educativos a través de un formulario electrónico. Los resultados obtenidos revelan que se optó por la continuidad de las actividades, a través de la enseñanza a distancia, proyectando en los directivos el desafío de organizar, junto con el equipo pedagógico, la dinámica del proceso de enseñanza-aprendizaje a partir del uso de las herramientas tecnológicas disponibles, así como en la elaboración. folletos con contenido de libros de texto; no hubo entrenamiento específico para ese momento; y la demanda de trabajo aumentó, registrándose demandas por parte de las familias de los estudiantes sobre las metodologías utilizadas por las escuelas. Además de los dilemas existentes: minimización de recursos, falta de participación y autonomía, etc. - El contexto de la pandemia proyectaba en los directivos el desafío de reinventarse en su desempeño profesional.

Palabras clave: Organización del Trabajo Pedagógico; Gestión educativa; Formación; Pandemia.

\section{INTRODUÇÃO}

O contexto pandêmico da Covid-19 - resultante da transmissão em massa do SARS-CoV-2 (Coronavírus) - ocasionou a urgente (re)adequação da sociedade, visibilizando desafios na organização de setores e sujeitos para o enfrentamento deste período, com intensa mobilização das ciências pela criação de uma vacina capaz de impedir o avanço do vírus que já alcança um quantitativo mundial de 51.636.989 casos confirmados da doença e 1.275.124 mortes.

No Brasil, os dados revelam um total de 5.701.283 confirmações, seguido por 162.842 óbitos ${ }^{4}$, num contexto em que as divergências na atuação governamental são colocadas em visibilidade, principalmente, no que diz respeito ao bem estar e segurança da população, como: na insistência, pelo atual presidente da república, Jair Bolsonaro, quanto ao uso de Cloroquina como medicamento eficaz no tratamento da doença ${ }^{5}$, mesmo as autoridades e especialistas em saúde afirmando o contrário pelo alto poder de letalidade; e o recente caso de suspensão e, conseguinte, retomada dos testes com a vacina chinesa Coronavac pela Agência Nacional de Vigilância Sanitária (Anvisa) ${ }^{6}$, já nas fases finais do estudo. Tais polêmicas reforçam a sobreposição dos interesses governamentais, em detrimento do capital e sua expansão, sob os anseios e necessidades coletivas, minimizando o compromisso com a proteção da vida (SANTOS, 2020).

As condições socioeconômicas visibilizadas indicam uma preocupação quanto à expansão dos casos e a desassistência social das classes menos favorecidas, podendo ocasionar uma verdadeira luta pela sobrevivência, na qual o vírus torna-se apenas um detalhe (ORSO, 2020). Nesse sentido, reafirma-se

${ }^{4}$ Dados atualizados em $11 / 11 / 2020$ às 15 h55 no Portal Coronavírus, disponível em: https://news.google.com/covid19/map?hl=pt-BR\&mid=/m/015fr\&gl=BR\&ceid=BR:pt-419.

${ }^{5}$ Conforme notícia disponível em: https://www.terra.com.br/vida-e-estilo/saude/bolsonaro-30-das-mortesseriam-evitadas-com-cloroquina,b4d6c70ee9f1e906acf267e3e1b8b780b6pc47y2.html.

${ }^{6}$ Notícia disponível em: https://noticias.uol.com.br/saude/ultimas-noticias/redacao/2020/11/09/anvisadetermina-interrupcao-de-estudos-clinicos-sobre-coronavac.htm. 
a necessidade de ações mais severas que possam coibir aglomerações e garantir proteção e segurança a população brasileira, já que, contraditoriamente, enquanto que escolas, universidades e instituições sociais - essenciais na cotidianidade - permanecem fechadas, serviços de bares, academias e, até mesmo, a realização das eleições municipais estão mantidas, entendendo que estes últimos são benéficos ao crescimento e expansão do capital (SAVIANI, 2020).

Momento que deveria oportunizar a junção de esforços coletivos em prol do enfrentamento a pandemia, tornou-se um espaço de articulações favoráveis aos interesses das forças detentoras do poder, esmaecendo o campo dos direitos públicos quanto à assistência e proteção dos cidadãos (SOARES; COLARES, 2020). Tais constatações são reforçadas nas falas de Jair Bolsonaro, contemplando o desprezo pelo vírus, insistência na retomada das atividades laborais, a preocupação com a preservação da economia e os discursos de ódio propagados durante a pandemia, uma vez que "[...] depois de o Brasil contabilizar um número elevado de pessoas mortas pela contaminação [...] o presidente veio [...] relativizar o perigo da pandemia viral, adjetivando a doença [...] como uma "gripezinha [...]" (FONSECA; SILVA, 2020, p. 64), revelando "[...] comportamentos, ideias e atuações inconsequentes sobre um problema de natureza grave [...]" (SOARES; COLARES, 2020, p. 28).

Se não bastasse a pandemia da Covid-19, outros problemas agravaram-se neste período, ocorrendo de forma silenciosa, como os crescentes desmatamentos e um projeto de privatização sobre a Amazônia brasileira ${ }^{7}$, os incêndios na região do Pantanal ${ }^{8}$ e, recentemente, a falta de energia elétrica no Estado do Amapá9. Além disso, após a realização das eleições americanas e a derrota de Donald Trump, figura exaltada pelo atual presidente do Brasil, Jair Bolsonaro veio a público afirmar que este é um "país de maricas" (Brasil), ao mesmo tempo em que, estupidamente, levantou a hipótese de uma guerra armada contra os Estados Unidos ${ }^{10}$. Tais ações reforçam a precariedade que o país se encontra sob a condução de um governo excludente, opressor e ideológico (ORSO, 2020).

Atualmente, da condição em que "[...] a humanidade vivencia um confinamento forçado que paralisou mais de 3,5 bilhões de pessoas [...]" (ORSO, 2020, p. 2), ressalta-se, de acordo com Santos (2020), que a crise da Covid-19 não está contraposta a uma situação de normalidade, pois o mundo já vivencia este agravamento social desde o avanço do neoliberalismo em 1980 . Do contrário, a pandemia apenas agravou uma condição de crise já existente, embasando-se no fato de que "[...] o capital não dá tréguas [...]", aproveitando-se do momento atípico para induzir um sentimento de "[...] apreensão, inquietação, espanto, assombro, preocupação e pânico [...]" (ORSO, 2020, p. 2-3). Significa, portanto, afirmar que o Coronavírus não causou desigualdades nas estruturas sociais, apenas corroborou em sua visibilidade, uma vez que já existiam na sociedade do capital, em sua essência opressora, sem esquecer que qualquer quarentema é discriminatória e reforça a injustiça, a exclusão e o sofrimento (SANTOS, 2020).

\footnotetext{
${ }^{7}$ Conforme notícia disponível em: https://www.dw.com/pt-br/governo-bolsonaro-pratica-nacionalismoseletivo-na-amaz\%C3\%B4nia/a-54956948.

${ }^{8}$ Ler a matéria em: https://noticias.uol.com.br/meio-ambiente/ultimas-noticias/redacao/2020/10/01/inpepantanal-tem-mais-de-8-mil-focos-de-incendio-no-mes-2020-e-pior-ano.htm.

${ }^{9}$ Notícia disponível em: https://g1.globo.com/ap/amapa/noticia/2020/11/12/apagao-chega-ao-10o-dia-noamapa-e-governo-anuncia-novos-horarios-de-rodizio.ghtml.

${ }^{10}$ Informações de acordo com a notícia publicada em: https://noticias.uol.com.br/ultimasnoticias/rfi/2020/11/11/com-pais-de-maricas-bolsonaro-mistura-homofobia-e-indecencia-diz-imprensainternacional.htm.
} 
No que tange ao campo educacional, a pandemia também introduziu uma série de dilemas organização da dinâmica de ensino, atendimento educacional aos estudantes, garantir a continuidade das aulas, etc. - que, somando-se as desigualdades sociais visibilizadas, projetou no trabalho de gestores, docentes e comunidade educacional a necessidade de (re)formulação dos processos pedagógicos e da própria atuação profissional diante de um atípico momento, cobrando-lhes a adoção de estratégias que garantam uma propensa qualidade no ensino, premissa central das políticas públicas educacionais em vigência (SAVIANI, 2020).

Sob essa perspectiva, o estudo visa analisar a atuação de gestores educacionais frente à dinâmica de organização do trabalho pedagógico no curso de uma pandemia, revelando práticas, desafios e o lugar da formação nesse processo. Utiliza-se como lócus a região Oeste do Estado do Pará. Da questão problema, decorrem os seguintes objetivos: compreender a crise da Covid-19 no Brasil e suas ações no campo educacional brasileiro; identificar os percursos da pandemia na região Oeste do Pará, especialmente, na realidade das escolas públicas; e discutir práticas e desafios no trabalho de gestores educacionais, no Oeste do Pará, frente à dinâmica de organização do trabalho pedagógico no contexto pandêmico.

As análises constituídas resultam de uma pesquisa empírica - caracterizada pela observação e o uso de "[...] instrumentos científicos que possa trazer maiores contribuições para o desenvolvimento do conhecimento [...] preenchendo lacunas existentes na compreensão dos diversos fenômenos que o envolvem" (THEÓPHILO, 1998, p. 1) - contemplando, entre as técnicas de coleta de dados, o uso de levantamento bibliográfico e documental, aplicação de entrevistas semiestruturadas e observação. Dividiu-se a realização do estudo em dois momentos: primeiro, pela análise da percepção dos gestores educacionais sobre o tema, possível pela utilização de formulário eletrônico; e em segundo, na observação de ações e realidades vivenciadas por estes sujeitos na pandemia, a partir da dinâmica do ensino remoto.

Entre os sujeitos da pesquisa estão seis (6) gestores educacionais, sendo dois (2) atuantes em instituições que ofertam a modalidade da Educação Infantil e Anos Iniciais do Ensino Fundamental, dois (2) em escolas de Anos Finais do Ensino Fundamental, seguido por outros dois (2) que atuam no Ensino Médio, contemplando a rede pública estadual e municipal da região Oeste do Pará. Seguindo princípios éticos, os entrevistados encontram-se identificados por números arábicos $(1,2$, $3,4,5,6)$, antecedidos da sigla GD (Gestor Educacional).

Da base teórica selecionada, contemplam-se, inicialmente, as discussões de Orso (2020), Santos (2020), Saviani (2020) e Soares; Colares (2020), autores que tratam do contexto pandêmico e seus efeitos no campo educacional, seguido por outros estudiosos do tema. Contemplam-se ainda relatórios técnicos sobre a pandemia no lócus de estudo.

Para efeito de organização, o artigo está composto de três blocos: a crise da Covid-19 e a educação pública brasileira, compreendendo, a partir de um viés teórico-conceitual, o contexto pandêmico e suas ações na educação; a pandemia na região Oeste do Pará, com reflexões dos percursos da pandemia na realidade das escolas públicas no lócus do estudo; e o trabalho pedagógico no Oeste do Pará: organização, desafios e novos contextos, tratando da atuação de gestores educacionais na organização do trabalho pedagógico sob um atípico momento. A seguir, discute-se cada um. 


\section{A CRISE DA COVID-19 E A EDUCAÇÃO PÚBLICA BRASILEIRA}

A pandemia da Covid-19 e seus efeitos não se tratam de um acontecimento passageiro, ou seja, superado com a imunização da população pela criação de uma vacina. Do contrário, levando em conta a gravidade dos prejuízos condicionados por este atípico momento no campo educacional com atrasos, interrupções e a inserção de novas metodologias didático-pedagógicas, mesmo diante de desigualdades no acesso a estes recursos - o contexto pandêmico tende a introduzir múltiplos desafios no cotidiano escolar (ORSO, 2020), pós-pandemia, compreendendo que mesmo com a opção de continuidade das atividades, via ensino remoto, não se pode negar o risco de uma possível minimização na qualidade do processo ensino-aprendizagem, podendo levar ao fracasso, desmotivação, evasão e repetência dos estudantes, principalmente, aqueles em situações desconfortáveis e/ou desiguais (SAVIANI, 2020).

Vivencia-se hoje o dilema do "novo normal" na educação (SANTOS, 2020), em que novas habilidades e competências são postas em ênfase, tanto aos profissionais como aos estudantes e seus familiares, diante dos desafios na condução de processos e dinâmicas educacionais, num espaço de ineficiências constantes pelo poder público (SAVIANI, 2020). Outrora, tão criticada quanto a sua inserção no campo educacional, as tecnologias ganham reconhecimento e importância na rotina escolar em tempos de pandemia como saída na continuidade das aulas e demais atividades (SOARES; COLARES, 2020), apesar de tratar-se de um acesso ainda desigual.

Ao tratar da contribuição das tecnologias para o atípico momento, estudos realizados por Cruz, Borges e Nogueira Filho indicam que os profissionais da educação, principalmente, aqueles inseridos em contextos onde o atraso tecnológico é real, como na região norte do país, a exemplo, necessitam de formação para o trabalho com as tecnologias educacionais, indicando que "76\% buscaram recentemente formas para [...] aprimorar seus conhecimentos; $67 \%$ alegaram ter necessidade de aperfeiçoamento [...] para o uso pedagógico" (2020, p. 13). Do novo contexto educacional, tendo como plano de fundo as tecnologias disponíveis, as ferramentas mais utilizadas na comunicação são: Whatsapp (83\%), Facebook (44\%), Ambientes Virtuais de Aprendizagem (34\%), E-mail (25\%) e Youtube $(7 \%)$, por meio do uso do celular (PENÍNSULA, 2020).

Refletir as condições dos estudantes para a inserção no novo modelo de ensino, por meio das tecnologias educacionais, tem constituído amplo debate no que tange a garantia e qualidade da aprendizagem, no cumprimento do calendário escolar e da nova rotina para acompanhamento das atividades direto do ambiente familiar. Tais discussões encaminharam uma crítica negativa em torno da realização do Exame Nacional do Ensino Médio (Enem), sendo adiado para o próximo ano. Aproveitando-se do momento, a atuação governamental tem sido meticulosa no avanço de um projeto de privatização sobre o ensino público, conforme discutido por Soares ao afirmar que:

Quando se anuncia a chegada do COVID-19 no Brasil um dos primeiros passos dos governantes para "conter" o vírus é decretar o fechamento das escolas, simbolizando assim que a situação não estava "normal". Os prazos dos decretos seguem sendo ampliados e a pressão pela continuidade dos estudos fez com que se tirasse da gaveta um projeto que há muito tempo fazia parte das aspirações dos governos e empresas privadas de educação: a educação a distância (EAD). Do dia para a noite essa modalidade que até então era proibida como ferramenta prioritária na educação básica, torna-se a solução pragmática para o momento da crise pandêmica (2020, p. 6-7). 
A transposição de uma realidade presencial para o ambiente virtual tem desencadeado uma série de questionamentos no sentido da formação integral do estudante, diante da seguinte indagação: nesse modelo de ensino, os alunos apreendem de forma efetiva ou apenas cumprem burocracias legais para aprovação escolar? Responder esta pergunta se faz necessário, porém, é urgente refletir as condições, processos e ações desenvolvidas no campo educacional na pandemia, contemplando o currículo, a organização didático-metodológica, a percepção discente, o fazer docente e o trabalho na gestão para a concretude do ensino (SOARES; COLARES; HORA, 2020).

Nesse contexto, introduziu-se a dinâmica do ensino remoto, cuja prática indica uma (re)formulação de ações, reflexões e transformações na realidade educacional (SAVIANI, 2020), sem perder de vista as precariedades já existentes. O ensino remoto "surgiu [...] para suprir a ausência das aulas [...] posto como um substituto do ensino presencial excepcionalmente nesse período da pandemia em que a educação presencial se encontra interditada" (SAVIANI, 2020, p. 5). Portanto, não pode equivaler este modelo ao ensino presencial, bem como não está associado à modalidade da Educação a Distância, já que esta possui uma série de requisitos e legislação específica consolidada. Eis a primeira ideia a ser desconstruída, pois, de acordo com Saviani, algumas observações devem ser analisadas para a efetividade do ensino remoto, entre elas:

a) o acesso de todos os alunos ao ambiente virtual propiciado pela aparelhagem representada por computadores, celulares e similares;

b) considerando que alunos e professores devam estar confinados nas suas residências, estas deverão estar todas equipadas com acesso à internet;

c) é preciso que todos os estudantes preencham os requisitos mínimos para acompanharem, com proveito, o ensino remoto. Ou seja, é preciso que todos estejam não apenas alfabetizados em sentido estrito, mas também em sentido funcional e, mais do que isso, não sejam analfabetos digitais (2020, p. 5-6).

Partindo deste pressuposto, ressalta-se que houve a ampliação do trabalho didático-pedagógico para além dos muros das escolas, alcançando as famílias dos estudantes que passaram a assistir, intervir e criticar os processos desenvolvidos na dinâmica do ensino remoto, uma vez que a casa é a "nova sala de aula", consolidando a premissa de que:

[...] estamos diante de uma dicotomia na educação escolar, principalmente, daqueles ainda em atividades durante a pandemia: de um lado, as expectativas dos estudantes e de seus familiares; do outro, as fragilidades e desafios da atuação docente e a incorporação de suas práticas nas tecnologias disponíveis, momento de tensão e desencontros na função educativa (SOARES; COLARES; HORA, 2020, p. 5).

Todavia, mesmo diante de inúmeros dilemas, a pandemia "[...] tem proporcionado algum tipo de aprendizado [...] ao uso e incorporação de novas metodologias e processos educacionais, superando [...] medos", configurando-se como espaço "[...] valioso para ratificar a valorização da função docente como um elemento fundamental na sociedade em crise" (SOARES; COLARES; HORA, 2020, p. 5). Outro ponto a ser refletido mostra-se na decisão - pelos órgãos educacionais - de continuidade das aulas com mínimas investigações sobre as condições dos estudantes e de seus familiares para um acompanhamento exitoso (SOARES; COLARES, 2020), fator negativo que reforçou desigualdades e inseriu novos dilemas na educação pública.

Em estudos sobre o contexto pandêmico, Cruz, Borges e Nogueira Filho apresentam quatro constatações sobre a dinâmica do ensino remoto, alegando que: 1) soluções de ensino remoto podem 
contribuir durante a pandemia, mas considerando o efeito limitado, devem receber atenção redobrada no planejamento de retorno às aulas; 2) é preciso mitigar as condições heterogêneas de acesso dos estudantes, ofertando diferentes soluções à distância; 3) ensino remoto não é sinônimo de aula online; 4) mesmo a distância, a atuação docente é central para o êxito no processo educacional (2020, p. 6-13). Além disso, enquanto as redes públicas de ensino interrompiam suas atividades no início da pandemia, instituições particulares já introduziam formas de manter o suporte à distância aos estudantes (PENÍNSULA, 2020).

Das principais demandas identificadas no campo de atuação profissional durante a pandemia, entre docentes e gestores, estão: a necessidade de maior oferta de treinamentos para o ensino remoto, apoio pedagógico no ambiente virtual e apoio psicológico/emocional (PENÍNSULA, 2020), destacando que, além de desafios logístico-estruturais, os profissionais permanecem expostos a riscos de saúde, já que se ampliaram as demandas e novos problemas emergiram no cotidiano. Portanto, neste atual contexto, faz-se necessário redobrar os cuidados com o bem estar dos profissionais, deixando a preocupação com a qualidade do ensino para o retorno as atividades presenciais, considerando que "é hora de focar em amenizar os danos no curto prazo, mas sem perder de vista que é no planejamento da volta às aulas que reside a chance de, efetivamente, enfrentarmos o desafio que se impõe" (CRUZ; BORGES; NOGUEIRA FILHO, 2020, p. 15).

Assim, confirma-se que a pandemia tem ocasionado uma série de conflitos na escola pública brasileira, induzindo a continuidade das demandas e processos educacionais diante de um modelo equivocado de ensino (SAVIANI, 2020). Se já é difícil imaginar o desafio dos estudantes e seus familiares na dinâmica do ensino remoto, imagine no que tange a atuação dos gestores educacionais diante da organização do trabalho pedagógico e das inúmeras responsabilidades atribuídas a estes. No tópico seguinte, discutem-se os percursos da pandemia nas escolas públicas da região Oeste do Pará.

\section{A PANDEMIA NA REGIÃO OESTE dO PARÁ}

O Estado do Pará, composto por 144 municípios, contempla uma população de, aproximadamente, 8.334.346 habitantes e área territorial de 1.247.954,666 km² (CRUZ; MONTEIRO, 2020), o segundo maior em extensão territorial nacional. Destacam-se ainda a existência de subdivisões geográficas, como a região Oeste do Pará, lócus do estudo, composta por 23 municípios paraenses, conforme destaque na Figura de No 1.

É válido lembrar que tais municípios ainda apresentam condições desfavoráveis de segurança, saneamento básico, geração de emprego e renda, acesso aos serviços de educação e saúde, etc., com ausências e abandonos no campo dos direitos. Nesse sentido, partindo da condição de desigualdades já existente antes da pandemia, ressalta-se que a crise da Covid-19 impactou profundamente a organização destes municípios, revelando estruturas precárias em hospitais para atendimento dos casos na região, concentrando os mais graves em Santarém/PA por apresentar melhor estrutura. Visando refletir os dados da pandemia no lócus do estudo, o Quadro de No 1 apresenta um panorama da Covid-19 nos municípios da região Oeste do Pará. 
Figura 1: Mapa geográfico da região Oeste do Pará.

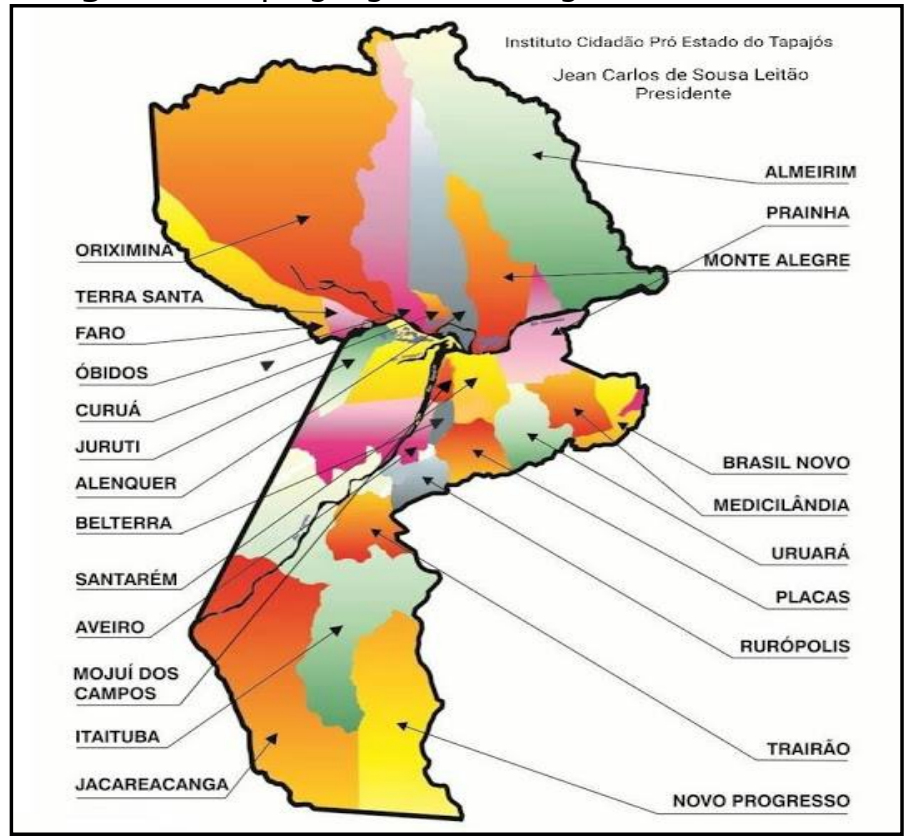

Fonte: https://www.tapajosmeuestado.com.br/2018/02/conheca-estrutura-do-estado-do-tapajos.html.

Quadro 1: Panorama da Covid-19 na região Oeste do Pará.

\begin{tabular}{|c|c|c|c|}
\hline \multicolumn{4}{|c|}{$\begin{array}{c}\text { PANORAMA DA COVID-19 NA REGIÃO OESTE DO PARÁ } \\
\text { (Dados atualizados em 11/11/2020) }\end{array}$} \\
\cline { 2 - 4 } MUNICÍPIOS & \multicolumn{3}{c|}{ CASOS REGISTRADOS DA DOENÇA } \\
\cline { 2 - 4 } & CONFIRMADOS & RECUPERADOS & ÓBITOS \\
\hline Alenquer & 1.484 & 1.356 & 30 \\
\hline Almeirim & 267 & 245 & 18 \\
\hline Aveiro & 445 & 439 & 5 \\
\hline Belterra & 556 & 541 & 14 \\
\hline Brasil Novo & 764 & 723 & 16 \\
\hline Curuá & 790 & 779 & 4 \\
\hline Faro & 407 & 407 & 0 \\
\hline Itaituba & 6.619 & 6.454 & 99 \\
\hline Jacareacanga & 1.700 & 1.683 & 14 \\
\hline Juruti & 2.418 & 2.219 & 71 \\
\hline Medicilândia & 1.844 & 1.808 & 16 \\
\hline Mojuí dos Campos & 477 & 458 & 14 \\
\hline Monte Alegre & 1.586 & 1.496 & 28 \\
\hline Novo Progresso & 895 & 821 & 14 \\
\hline Óbidos & 2.853 & 2.741 & 47 \\
\hline Oriximiná & 4.793 & 4.549 & 58 \\
\hline Placas & 524 & 518 & 5 \\
\hline Prainha & 594 & 534 & 25 \\
\hline Rurópolis & 1.670 & 1.643 & 12 \\
\hline Santarém & 11.091 & 10.639 & 217 \\
\hline Terra Santa & 408 & 362 & 9 \\
\hline Trairão & 366 & 356 & 4 \\
\hline Uruará & 1.233 & 1.209 & $\mathbf{7 3 6}$ \\
\hline TOTAL GERAL & $\mathbf{4 3 . 7 8 4}$ & $\mathbf{4 1 . 9 8 0}$ & 5 \\
\hline
\end{tabular}

Fonte: Boletins epidemiológicos disponíveis no Portal Coronavírus da Secretaria de Saúde do Pará (https://www.covid-19.pa.gov.br/public/dashboard/41777953-93bf-4a46-b9c2-3cf4ccefb3c9), 2020. 
Em análise ao Quadro No 1, os números revelam um total de 43.784 confirmações da doença e 41.980 recuperações, seguido por lastimáveis 736 óbitos, contexto de alerta diante do abandono e desassistência social. Além disso, enquanto pessoas estão morrendo pela ausência de leitos e/ou equipamentos respiratórios, inúmeros desvios de recursos ocorreram no orçamento da saúde pública no Estado ${ }^{11}$, contemplando, em alguns municípios, a intervenção da polícia federal em secretarias municipais de saúde, com a apreensão de bens e pessoas. Tais acontecimentos apenas reforçam a intervenção governamental em prol de seus interesses, abandonando o compromisso com a população (SAVIANI, 2020).

No campo educacional, vale destacar que o Pará possui hoje, aproximadamente, 10.800 estabelecimentos da Educação Básica, sendo 9.880 da rede pública e 920 da privada, contemplando um percentual de 2.328.439 matrículas na Educação Básica, com 2.094.457 em instituições públicas de ensino e 233.982 em instituições privadas (CRUZ; MONTEIRO, 2020). Sob tal realidade, revela-se um contexto educacional em constantes desafios, na dinâmica do ensino remoto, com ausência de formação, sobrecarga de trabalho, inexistência de materiais didático-pedagógicos e intensificação das cobranças governamentais para a efetividade de uma projetável qualidade no ensino (PENÍNSULA, 2020).

Com as aulas presenciais suspensas por decretos estaduais e municipais, encontrou-se nas tecnologias uma possibilidade de contato com os estudantes durante a pandemia, porém, o que não se esperava era a obrigatoriedade de continuação das atividades educacionais no ambiente virtual, fator que projetou um amplo desafio sobre as escolas paraenses, já que não dispõem de equipamentos para a aplicabilidade da dinâmica. Para ter uma ideia, muitas instituições, principalmente, na região oeste do Pará, não possuem acesso à internet na própria escola, quanto mais recursos tecnológicos para utilização em massa. Tudo isso, sem esquecer-se da realidade de instituições ribeirinhas e/ou do campo, situadas em contextos logísticos deficitários.

Quanto às ações desenvolvidas na pandemia, em algumas instituições os estudantes receberam auxílio de alimentação escolar e atividades impressas, formas encontradas para minimizar as desigualdades reveladas. Em linhas gerais, não se viu muitos investimentos, por parte dos governos, no campo educacional, funcionando apenas como alternativas para demonstrar que algo está sendo feito.

Empiricamente, observa-se nas realidades educacionais que houve a demissão em massa de servidores contratados da educação, principalmente, profissionais docentes, sobrecarregando os demais das instituições. Pode-se inferir que, quanto mais se pensou em diminuir o número de trabalhadores visando reduzir gastos, maior sobrecarregou-se o trabalho dos gestores e demais profissionais, condicionando-os ao desafio de (re)organização das tarefas em prol do cumprimento de um ensino desfavorável as atuais condições da região Oeste (SOARES; COLARES, 2020).

Ao adentrar nos dados de um relatório constituído pelo Tribunal de Contas dos Municípios do Estado do Pará (TCM/PA), envolvendo todos os municípios da região Oeste, contemplam-se algumas

\footnotetext{
${ }^{11}$ Conforme notícia veiculada em: https://g1.globo.com/pa/para/noticia/2020/09/29/onze-pessoas-sao-presasna-operacao-da-pf-que-investiga-supostos-desvios-de-recursos-da-saude-envolvendo-governo-dopa.ghtml.
} 
questões que reforçam o desafio de continuidade das aulas e o comprometimento com o processo ensino-aprendizagem durante a pandemia, conforme sistematizadas no Quadro de № 2.

Quadro 2: Questões sobre a organização do ensino nos municípios do Estado do Pará na pandemia.

\begin{tabular}{|l|c|c|}
\hline \multicolumn{1}{|c|}{ A ORGANIZAÇÃO DO ENSINO NOS MUNICÍPIOS PARAENSES NA PANDEMIA } \\
\hline \multicolumn{1}{|c|}{ PERGS } & SIM & NÃO \\
\cline { 2 - 3 } & & \\
\hline $\begin{array}{l}\text { 1. O município vem realizando ações que contemplem os alunos da rede } \\
\text { pública municipal de ensino, e garantam o acesso a conteúdo de aulas } \\
\text { mediante metodologias de ensino à distância e aplicação de atividades } \\
\text { pedagógicas não presenciais? }\end{array}$ & $65,04 \%$ & $34,96 \%$ \\
\hline $\begin{array}{l}\text { 2. O município efetuou parceria colaborativa com o Poder Público na } \\
\text { articulação com canais de TV e de rádio disponíveis, para oferta de } \\
\text { conteúdos pedagógicos com alcance ao maior número de alunos } \\
\text { possíveis? }\end{array}$ & $10,57 \%$ & $89,43 \%$ \\
\hline $\begin{array}{l}\text { 3. O município apoia o corpo docente da rede pública municipal no } \\
\text { desenvolvimento de conteúdos e atividades a distância que promovam e } \\
\text { estimulem a aprendizagem dos alunos? }\end{array}$ & $78,86 \%$ & $21,14 \%$ \\
\hline $\begin{array}{l}\text { 4. O município publicou normas para regulamentar as metodologias } \\
\text { utilizadas no ensino a distância, bem como para o aproveitamento das } \\
\text { atividades pedagógicas não presenciais, visando o cumprimento da carga } \\
\text { horária mínima anual prevista em lei, e deste modo, possibilitar o } \\
\text { acompanhamento e avaliação por parte dos órgãos interessados? }\end{array}$ & $59,35 \%$ & $40,65 \%$ \\
\hline $\begin{array}{l}\text { 5. O município realizou a distribuição dos alimentos em estoque para as } \\
\text { famílias dos alunos da rede municipal? }\end{array}$ & $92,68 \%$ & $7,32 \%$ \\
\hline $\begin{array}{l}\text { 6. O Conselho Municipal de Educação - CME está acompanhando as } \\
\text { medidas planejadas e/ou adotadas pela Secretaria, referentes ao } \\
\text { cumprimento da carga horária anual, calendário escolar e outras? }\end{array}$ & $70,73 \%$ & $29,27 \%$ \\
\hline
\end{tabular}

Fonte: TCM/PA, 2020.

Ao analisar o Quadro de No 2 é perceptível que este momento tem sido desafiador na organização do trabalho pedagógico - tanto aos órgãos de educação quanto na atuação dos gestores educacionais - uma vez que prevalece a ideia de desencontros nas metodologias que garantam a adaptação das atividades de ensino no ambiente virtual, não indicando um consenso entre as redes públicas educacionais. Enquanto que, insistentemente, defende-se o uso da internet, a parceria com as emissoras de rádio e televisão locais torna-se enfraquecida, cujos instrumentos seriam mais favoráveis a transmissão das atividades, pois, a maioria dispõe destes recursos em casa (PENÍNSULA, 2020), o que tornaria o acesso mais oportunizado.

Curiosamente, os órgãos municipais informam que apoiam o corpo docente, mas tais afirmações não são prováveis mediante um desassistencialismo pedagógico, com a ausência de processos formativos nas novas demandas do ensino. Assim, quando questionados sobre o alcance das ações no sentido de contemplar os estudantes, através dos meios de comunicação, os entrevistados do relatório informaram que 55,28\% realizam ações não presenciais e conseguem alcançar os estudantes, 9,76\% realizam ações, mas não alcançam todos os alunos, seguido por 34,96\% que não realizam ações à distância. Ao pensar os percursos da pandemia no Oeste do Pará e seus efeitos na escola pública, destaca-se que:

[...] 35\% dos municípios analisados não vêm desenvolvendo ações que contemplem aos alunos, o acesso a conteúdo de aulas mediante o ensino à distância, e/ou aplicação de atividades pedagógicas não presenciais [...]; enquanto que $65 \%$ 
declararam estar ofertando algum tipo de atividade pedagógica de forma remota [...]. $55,28 \%$, informaram que conseguem alcançar a todos os estudantes, inclusive os que vivem em situações socioeconômicos mais vulneráveis e/ou que residam em localidades de difícil acesso de comunicação (TCM/PA, 2020, p. 34).

Nesse sentido, revela-se que "[...] 54,47 dos municípios estão desenvolvendo ações de fornecimento de conteúdos mediante ensino à distância [...]", mas sem estratégias que possam efetivamente aferir o conhecimento, desempenho e avaliação escolar, ressaltando o fato de que "a maior parte dos municípios (97,56\%) está planejando a reorganização do calendário escolar para retorno às aulas de forma gradativa, a partir da flexibilização do isolamento social [...]" (TCM/PA, 2020, p. 34). Portanto, a pandemia na região Oeste impactou a escola pública no sentido de sua paralização quanto ao processo ensino-aprendizagem, visibilizando poucas atividades em desenvolvimento, apenas como respostas as exigências governamentais, mas sem indícios de positividade no desenvolvimento estudantil e educacional.

\section{O TRABALHO PEDAGÓgICO NO OESTE DO PARÁ: ORGANIZAÇÃO, DESAFIOS E NOVOS CONTEXTOS}

Partindo da percepção e observação na atuação de seis (6) gestores educacionais diante da organização do trabalho pedagógico - durante a pandemia na região Oeste do Pará - obteve-se alguns resultados que possibilitam uma reflexão sobre os desafios, práticas e novos contextos implantados na organização do processo ensino-aprendizagem e na condução das instituições numa dinâmica equivocada de ensino (SAVIANI, 2020), conforme discutidos a seguir.

Inicialmente, com a paralisação tardia das atividades presenciais nestes municípios, optou-se pela continuidade das atividades, mesmo sem um plano de ações para o contexto pandêmico, pois "fomos convocados para uma reunião na secretaria municipal e colocou-se a possibilidade de continuar ou não as aulas, todos votaram e venceu a proposta de continuação, mesmo sem discutir como faríamos isso" (GD 3, 2020), já que naquele momento "parecia existir uma ordem superior estabelecida para a continuação das atividades, visto pela insistência do secretário na retomada das aulas firmando-se no discurso do não comprometimento do calendário letivo" (GD 6, 2020). Tais reflexões mostram o poder das decisões externas operantes sobre a educação pública, ignorando os anseios e necessidades coletivas reais (ORSO, 2020; SOARES; COLARES; OLIVEIRA, 2020).

No curso da pandemia e diante da decisão de continuidade das aulas, discutiram-se, a partir de reuniões com gestores, docentes e equipe pedagógica (coordenadores pedagógicos), possibilidades metodológicas viáveis a garantia do processo ensino-aprendizagem, optando nas instituições pela: entrega, aos estudantes, de atividades impressas (apostilas), com conteúdos dos livros didáticos; distribuição de chips de dados móveis para acesso a internet ${ }^{12}$ (ação visível apenas na rede estadual) e; criação de grupos no Whtasapp. Além disso, tem-se visibilizado na rede estadual a realização de aulas pela TV, direcionadas os alunos concluintes do $3^{\circ}$ Ano do Ensino Médio, alternativa encontrada para possibilitar uma condição menos desigual na realização do Enem. Assim, ao discutir os desafios da aprendizagem no ambiente familiar (casa), contemplam-se a preocupação de dois gestores ao afirmarem que:

\footnotetext{
${ }^{12}$ Conforme notícia veiculada em: http://www.seduc.pa.gov.br/noticia/10745-alunos-da-3--serie-do-ensinomedio-utilizam-o-chip-de-internet-para-reforcar-os-estudos.
} 
O maior problema que eu vejo nessa dinâmica de ensino remoto é fazer com que $o$ aluno realmente estude, que ele se sinta atraído pelas atividades ofertadas, pois, se na sala de aula já é difícil, imagina competir com a realidade de casa, com a televisão e outros entretenimentos disponíveis que podem tomar a atenção dos estudantes, deixando os estudos em segundo plano (GD 2, 2020).

Eu penso que o maior desafio é conciliar a rotina dos pais com os horários de atividades dos filhos, já que muitos pais trabalham fora de casa, mesmo na pandemia, o que pode acontecer de os estudantes não dedicarem seu tempo nas atividades, podendo ser uma experiência incerta. A princípio, imaginávamos que, com a ausência física do professor, os pais auxiliariam seus filhos, mas na prática isso não acontece, mas é o que temos e precisamos apostar todas as nossas forças nisso, ou pelo menos, até a pandemia acabar (GD 4, 2020).

As falas em destaque apresentam um contraponto entre a projeção de um ensino a distância (remoto) e a inexistência de um prévio estudo sobre as condições necessárias ao êxito do processo (SAVIANI, 2020), revelando a necessidade de um ensino significativo aos estudantes e não apenas pautado na resolução de questões e memorização de conteúdos, como tem sido feito pelas instituições. É visível ainda o desconforto das famílias diante da necessidade de acompanhamento da dinâmica educativa, principalmente, aqueles que passam o dia fora de casa e ao retornarem procuram um ambiente tranquilo para descanso. Com a pandemia, a nova rotina noturna das famílias é auxiliar os alunos na resolução de extensas questões, registrando-se que "ao chegarem do trabalho, os pais vão ajudar os filhos nas atividades $e$, inaptos aos conteúdos, começam a ligar e/ou mandar mensagens, uma situação desconfortável, já que sou mãe e tenho um ambiente familiar para cuidar também" (GD 1, 2020). Sob tais realidades, pode-se indagar como fica este processo no contexto de famílias analfabetas e/ou que não possuem conhecimentos suficientes para auxiliar seus filhos? Um sério problema está posto nas metodologias utilizadas na continuidade das aulas, reforçando também a incompatibilidade de horários entre as rotinas do professor, gestor, estudantes e famílias (SOARES; COLARES; HORA, 2020).

De forma unânime, as instituições organizaram kits pedagógicos para distribuição entre os estudantes, contendo blocos impressos de questões, canetas, lápis, borrachas e máscaras, entregues aos responsáveis que assumiam o compromisso de retornar em sete dias com as atividades resolvidas para correção pelos professores. Essa alternativa foi utilizada por conta da constatação de que nem todos os estudantes possuíam acesso aos recursos tecnológicos, ressaltando que "antes de reiniciarmos, fizemos um levantamento se todos teriam condições de acompanhar as aulas, foi que constatamos que não, restando a alternativa de imprimir questões selecionadas, deixando as tecnologias apenas para troca de informações e dúvidas" (GD 5, 2020). Todavia, apesar de reconhecimento dos esforços na organização "democrática" do ensino, não podemos abandonar o fato de que tais ações não correspondem a aulas, diante de um enfraquecimento do processo ensinoaprendizagem do estudante em formação.

Em linhas gerais, o contexto pandêmico projetou nos gestores educacionais o desafio maior de organizar, junto a sua equipe pedagógica (coordenadores e docentes), a dinâmica do processo ensino-aprendizagem a partir do uso das ferramentas tecnológicas disponíveis, responsabilizando-os pelos acertos, falhas e demais acontecimentos no processo formativo dos estudantes da Educação Básica, conforme em destaque na fala de um dos entrevistados.

O maior desafio da nossa atuação se mostra nesse confronto: de um lado as altas exigências por um ensino de qualidade e do outro a ausência de condições para a realização do trabalho. Infelizmente, a pandemia está aí, não podemos fugir dela, 
mas a forma como jogaram essa responsabilidade sobre nós tem sido cruel, sem instrumentos adequados de trabalho e formação (GD 3, 2020).

A discussão mencionada pelo Gestor Educacional 3 reforça um ponto fundamental deste processo, a formação, compreendendo que trata-se de novas exigências, novos contextos e um novo ambiente de ensino. Nas realidades educacionais contempladas, destaca-se que não houve formações para a dinâmica do ensino remoto, ocorrendo apenas reuniões com as secretarias de educação que repassavam orientações sobre os processos e demandas. Tais profissionais revelam um despreparo na organização do trabalho pedagógico pelas ausências recorrentes em suas realidades, desde os insuficientes recursos tecnológicos, acesso precário à internet, falta de apoio familiar e inexistência de oportunidades de formação, ocorrendo "tudo na base do improviso" (GD 6, 2020).

Outra questão observada indica o aumento das demandas de trabalho, uma vez que têm ocorrido reivindicações, por parte das famílias dos estudantes, quanto às metodologias utilizadas pelas escolas, "culpando o professor e, até o gestor, de excessivas cobranças aos alunos, com tarefas que não eram trabalhadas na escola antes, visando dificultar tudo, principal reclamação oriunda das famílias" (GD 2 , 2020). Sob este argumento, é preciso investigar se as escolas têm cobrado muito dos estudantes ou apenas dado prosseguimento as atividades já desenvolvidas no ensino presencial. Tudo isso, sem esquecer-se de um distanciamento entre escola e família no decorrer dos anos, podendo justificar tais inferências duvidosas (SOARES; COLARES; OLIVEIRA, 2020). Além disso, os gestores alegam que o celular - principal instrumento de trabalho - tornou-se um verdadeiro "palco de conflitos". Concomitantemente, as relações com alguns docentes tem sido conflituosa, pois "eles não entendem o nosso papel, não estamos mandando neles, apenas repassando as orientações que a secretaria nos enviou sobre as metodologias de ensino" (GD 4, 2020), podendo inferir que tais acontecimentos podem estar associados a questões de natureza pessoal, fator recorrente nos conflitos entre gestor e comunidade (SOARES; COLARES; OLIVEIRA, 2020). Visando romper com a problemática, Vaiteka; Ghisleni (2019, p. 270) afirmam a necessidade de compreender que "[...] A aproximação entre o fazer dos gestores e o fazer docente é um fator que implica o sucesso da ação educativa", destituindo assim as estranhezas, confrontos e inoperâncias, especialmente, no curso de uma pandemia.

Somando-se aos desafios já existentes - minimização de recursos, ausência de participação e autonomia, falta de formação, etc. (SOARES; COLARES; OLIVEIRA, 2020; VAITEKA; GHISLENI, 2019) - o contexto pandêmico projetou nos gestores a necessidade de se reinventar em sua atuação profissional, revelando limitações, necessidades e contradições nos processos de organização do trabalho pedagógico, especialmente, no desvelamento de discrepâncias entre o escrito (as prescrições legais) e o feito (a ação concreta desenvolvida na prática), introduzindo uma realidade em que "As discussões, debates de ideias e contestações que já eram difíceis na estrutura verticalizada da escola, torna-se ainda mais complexo e até sem sentido em uma escola virtual" (SOARES, 2020, p. 9), enfraquecendo o compromisso com uma gestão democrática, a universalização do ensino, a garantia da qualidade e a formação omnilateral (SAVIANI, 2020) na escola pública, laica, gratuita e referenciada.

Chama-se atenção a acontecimentos, durante a pandemia, em municípios da região Oeste do Pará: o primeiro, na ação de distribuição da merenda escolar na rede municipal, onde algumas instituições enfrentaram problemas judiciais que, após denúncias, foram identificados a presença de produtos alimentícios com prazo de validade ultrapassados nas cestas básicas direcionadas aos estudantes; no segundo, o fato de que muitos pais e/ou responsáveis tiveram que contribuir financeiramente com 
as escolas para impressão das atividades educacionais, pois, mesmo com a utilização de recursos do Programa Dinheiro Direto na Escola (PDDE), as despesas ultrapassaram as verbas disponíveis. Estas sinalizações reforçam as ineficiências do poder público, conforme destaca Santos ao afirmar que:

As pandemias mostram de maneira cruel como o capitalismo neoliberal incapacitou o Estado para responder às emergências. As respostas que os Estados estão a dar à crise variam de Estado para Estado, mas nenhum pode disfarçar a sua incapacidade, a sua falta de previsibilidade em relação a emergências que têm vindo a ser anunciadas como de ocorrência próxima e muito provável. Estou certo de que nos próximos tempos esta pandemia nos dará mais lições e de que o fará sempre de forma cruel $[\ldots](2020$, p. 28).

No contexto de precarização do ensino e do trabalho na educação, destaca-se ainda o fato de que quatro (4) gestores, contemplados neste estudo, alegaram que foram contaminados pelo vírus durante a pandemia, pois "enquanto deveríamos estar em casa, isolados, estávamos e estamos na escola, ou andando de um lado para outro, buscando ajuda para colocar em prática uma educação de qualidade aos nossos alunos" (GD 1, 2020). Destes infectados, três (3) afirmaram que contraíram o vírus na escola por meio do contato rotineiro com outros sujeitos, mesmo diante da inviabilidade de comprovação da afirmativa.

Assim, tais percursos, encaminhados durante a pandemia, perpassando desafios e novos contextos na educação pública, reforçam um abandono, por parte do poder público, projetando nestes profissionais a concretude de uma dinâmica incerta, mas exigível pela base governamental. Paralelamente, figura-se nessa realidade a ideia de que continuar as aulas é mais importante do que a própria vida, fazendo jus aos gestores, coordenadores pedagógicos e docentes que permanecem ativos no ambiente físico da escola diante de novas exigências. Portanto, muito mais do que discutir a pandemia e seus efeitos na educação, é preciso avançar em uma análise mais ampla sobre o sentido da educação e do trabalho na dinâmica do ensino remoto, refletindo o aprendizado que tem se propiciado aos estudantes, as metodologias e suas avaliações empregadas no processo, bem como balizar os esforços lançados na organização do trabalho pedagógico. Na região Oeste do Pará, os caminhos ofertados nas discussões, nos colocam diante de uma realidade deficitária, excludente e desigual.

\section{CONSIDERAÇÕES FINAIS}

É evidente que o contexto pandêmico não tem sido colaborativo ao trabalho de gestores educacionais frente à organização do trabalho pedagógico, principalmente, pela ausência de formação, recursos e autonomia na condução do processo, uma vez que estes tem apenas replicado ordens externas, abandonando os anseios de sua própria realidade. Todavia, é reconhecível o esforço que os gestores vêm demonstrando em garantir a oferta de atividades aos estudantes na pandemia, apesar das intensas críticas direcionadas em sua atuação por parte das famílias dos estudantes e docentes. Constatações que nos ajudam a compreender os dilemas da gestão que, somando-se aos problemas já existentes, introduziu a necessidade de reinvenção profissional em um cenário de crise na educação pública brasileira.

Concomitantemente, a atuação dos gestores educacionais na pandemia coloca-os em uma situação prejudicial à vida, pela sua rotineira exposição em ambientes de risco, tudo em prol de garantir a continuidade e materialidade de ações na pandemia, sem esquecer-se do crescimento dos casos de 
Covid-19 na região. Soma-se a estes, a incipiência do poder público na aplicabilidade de ações mais efetivas para o êxito na dinâmica do ensino remoto, visibilizando ausências de um planejamento articulado com o aprendizado, a organização do ensino e avaliação do desempenho estudantil.

Sobre a opção de continuidade das aulas nos municípios da região Oeste do Pará, enxerga-se a paralisação do ensino remoto como a decisão mais assertiva no momento, aguardando o retorno das atividades presenciais, uma vez que não adianta dar prosseguimento a uma dinâmica educativa virtual sem recursos tecnológicos e serviços de internet, com desigualdades nas condições de acesso, falta de formação, etc. Talvez uma interrupção agora não seja tão prejudicial quanto a sua continuidade, pois, corre-se o risco de comprometer o aprendizado dos estudantes, bem como ocasionar a desmotivação e o abandono dos estudos e também problemas relacionados à saúde mental de gestores e docentes, compreendendo que o momento é delicado e não há estrutura para isso, principalmente, em escolas públicas da Amazônia, onde o atraso tecnológico e o abandono público são fatores reais.

Assim, no Oeste do Pará a pandemia constitui um desafio de mão dupla: o enfrentamento as necessidades e desigualdades educativas reveladas versus o abandono social e tecnológico já consolidado neste espaço, oriundo de um desassistencialismo por parte do capital, minimizando o compromisso social na região. Além disso, em um contexto que deveria possibilitar ações coletivas e protecionistas, revelam-se discursos de ódio e atuação incompatível com as realidades educacionais, acontecimentos que reforçam a essência opressora e excludente do próprio sistema vigente. Portanto, no lócus do estudo comtemplam-se desigualdades, incertezas e fragilidades, fatores que negativam o processo educacional e, cada vez mais, projetando a ideia de fracasso sobre a escola pública.

\section{REFERÊNCIAS}

CRUZ, Priscila; BORGES, João Marcelo; NOGUEIRA FILHO, Olavo. Nota técnica: ensino a distância na educação básica frente à pandemia da Covid-19. São Paulo: Todos pela Educação, 2020, p. 119. Disponível em: https://www.todospelaeducacao.org.br/_uploads/_posts/425.pdf?1730332266= Acesso em: 01 nov. 2020.

CRUZ, Priscila; MONTEIRO, Luciano. Anuário Brasileiro da Educação Básica 2020. São Paulo: Todos pela Educação; Editora Moderna, 2020. Disponível em:

https://www.todospelaeducacao.org.br/_uploads/_posts/456.pdf?1969753478/=\&utm_source=cont ent\&utm_medium=site-todos Acesso em: 03 nov. 2020.

FONSECA, André Dioney; SILVA, Silvio Lucas Alves da. O Neoliberalismo em Tempos de

Pandemia: o Governo Bolsonaro no contexto de crise da Covid-19. Ágora, v.22, n.2, jul./dez., 2020, p. 58-75. Disponível em: https://online.unisc.br/seer/index.php/agora/article/view/15461 Acesso: 08 nov. 2020.

ORSO, Paulino José. 0 novo coronavírus, a pedagogia histórico-crítica, a sociedade de classes e o internacionalismo proletário. Revista Exitus, v. 10, 2020, p. 01-54. Disponível em: http://www.ufopa.edu.br/portaldeperiodicos/index.php/revistaexitus/article/view/1432 Acesso em: 03 nov. 2020.

PENÍNSULA. Instituto. Relatório de Pesquisa - Sentimento e percepção dos professores brasileiros nos diferentes estágios do coronavírus no Brasil. São Paulo: IP, 2020. Disponível em: https://www.institutopeninsula.org.br/wp- 
content/uploads/2020/05/Covid19_InstitutoPeninsula_Fase2_at\%C3\%A91405-1.pdf Acesso em: 06 nov. 2020.

SANTOS, Boaventura de Sousa. A cruel pedagogia do vírus. Coimbra: Editora Almedina, 2020.

SAVIANI, Dermeval. Crise estrutural, conjuntura nacional, coronavirus e educação - 0 desmonte da educação nacional. Revista Exitus, v. 10, 2020, p. 1-25. Disponível em: http://www.ufopa.edu.br/portaldeperiodicos/index.php/revistaexitus/article/view/146 Acesso em: 15 out. 2020.

SOARES, Lucas de Vasconcelos; COLARES, Maria Lília Imbiriba Sousa. Educação e tecnologias em tempos de pandemia no Brasil. Debates em Educação, v. 12, n. 28, 2020, p. 19-41. Disponível em: https://www.seer.ufal.br/index.php/debateseducacao/article/view/10157 Acesso em: 20 out. 2020.

SOARES, Lucas de Vasconcelos; COLARES, Maria Lília Imbiriba Sousa; HORA, Dinair Leal da. Ensinar na Pandemia: dilemas atuais da docência. Revista Educação Básica em Foco (Anpae), v.1, n1, abr./jun., 2020, p. 1-6. Disponível em:

https://educacaobasicaemfoco.net.br/NumeroAtual/Artigos/Ensinar-na-Pandemia-dilemas-atuais-dadocencia-Lucas-MariaLilia-Dinair.pdf Acesso em: 04 nov. 2020.

SOARES, Lucas de Vasconcelos; COLARES, Maria Lília Imbiriba Sousa; OLIVEIRA, Lílian Aquino. Concepções de Gestão Educacional: práticas e desafios no interior da Amazônia. EDUCA Revista Multidisciplinar em Educação, Porto Velho, v. 7, n. 17, p. 232-256, jan./dez., 2020. Disponível em: http://www.periodicos.unir.br/index.php/EDUCA/issue/archive Acesso em: 16 out. 2020.

SOARES, Sávia Bona V. Coronavírus e a modernização conservadora da educação. In: SOARES, Sávia Bona V. et al (Org.). Coronavírus, educação e luta de classes no Brasil. Brasil: Editora Terra Sem Amos, 2020, p. 5-14.

TCM/PA. Relatório do levantamento diagnóstico da educação municipal diante da pandemia do Covid-19 aplicado aos municípios paraenses. Belém, PA: Núcleo de Fiscalização; Núcleo de Educação, 2020, p. 1-43. Disponível em: https://docplayer.com.br/193461106-Diagnostico-da-educacao-municipal-diante-da-pandemia-docovid-19.html Acesso em: 08 nov. 2020.

\section{THEÓPHILO, Carlos Renato. Algumas Reflexões sobre Pesquisas Empírica em}

Contabilidade. Caderno de Estudos, São Paulo, v. 10, n. 19, set./dez., 1998, p. 1-8. Disponível em: https://www.scielo.br/pdf/cest/n19/n19a01.pdf Acesso em: 10 nov. 2020.

VAITEKA, Sandra; GHISLENI, Ana Cristina. Ações de gestão e práticas pedagógicas: construindo pontes e aproximando caminhos. Revista Educar Mais, v. 3, n. 2, 2019, p. 269-281. Disponível em: http://periodicos.ifsul.edu.br/index.php/educarmais/article/view/1547 Acesso em: 03 nov. 2020. 